\title{
Uncommon presentation of the traumatic diaphragm rupture
}

\author{
Mustafa Silcan, Hayriye Gönüllü , Çağlar Alptekin, İsmet Parlak \\ İzir Bozyaka Training and Research Hospital, Department of Emergency Medicine, İzir, Turkey
}

\begin{abstract}
The clinical diagnosis of traumatic diaphragmatic rupture is difficult and it may even be more problematic if there are any concurrent injuries. In underdiagnosed patients, the symptoms may emerge in late terms. For an early and definitive diagnosis, the patient should be evaluated with a thoracoabdominal computerized tomography and a chest X-ray. This paper presents the case report of a patient diagnosed with the traumatic rupture of the diaphragm on the 2 nd day of trauma although the initial radiographic imaging tests had provided normal findings.
\end{abstract}

Key Words: Traumatic rupture of diaphragm, emergency department, uncommon presentation

\section{Introduction}

Acute diaphragmatic hernia is a result of diaphragmatic injury caused by a severe blunt or penetrating thoracoabdominal trauma (1). Traumatic diaphragm rupture (TDR) is a challenging condition for clinicians, resulting in the migration of intraabdominal organs into the thorax (2). This displacement can result in cardiovascular collapse by interfering with the mechanics of breathing, compressing the vena cava and preventing the normal filling of the heart by reducing the venous return (3). Furthermore, in the absence of hernia, it is usually difficult to diagnose TDR using conventional imaging methods (1). Therefore, thoracoabdominal CT and chest X-ray are used together for an early diagnosis $(1,4)$.

In this paper, we present a case report of a patient with TDR caused by a blunt trauma with a delayed diagnosis due to the early stage thoracoabdominal CT not showing any signs of TDR.

\section{Case report}

A 61-year-old male patient was referred to our hospital from an outpatient clinic, to which he had been admitted after several tree logs had fallen onto him. Before evaluation, Information on Informed Consent was provided. At the initial evaluation in the emergency department, the vital findings of the patient were stable, his general condition was good, and he was conscious, well oriented and cooperative. No abnormal physical examination findings were found except for sensitivity in the lumbar region. The patient's history showed that he only had chronic obstructive pulmonary disease (COPD) and there was no history of smoking or alcohol intake.

Hemoglobin was $13.3 \mathrm{gr} / \mathrm{dl}$ (13.6-17.2) and hematocrit was $39.1 \%(33-55)$ in laboratory tests performed at the external center. The first thoracoabdominal CT taken in the first few hours of the trauma showed no solid organ injury, free intraabdominal air or liquid. There were signs of a fracture of the right L1, L2, L3, and L4 transverse processes, left L2 transverse process and upper plateau of the anterior vertebra corpus. TDR was not determined (Figure 1a-1b). The findings of the abdominal Ultrasonography (USG) and the chest $\mathrm{X}$-ray (Figure 2a) taken in the emergency service of our hospital were normal. The results of the serial laboratory tests were within the reference ranges. The patient was hospitalized in the neurosurgery service to perform posterior spine fixation. On the second day of hospitalization, a control chest $\mathrm{X}$-ray and a control thoracoabdominal CT were undertaken due to the presence of respiratory distress. The CT scan revealed the total loss of aerated lung parenchyma, atelectasis, and air bronchograms in the left lung, diaphragm contour abnormalities on the left side of the diaphragm, and a diaphragmatic defect of approximately $6 \mathrm{~cm}$. As shown in Figure $2 \mathrm{~b}$, due to this defect, the splenic flexure of the colon, a part of the stomach and descending with the transverse colon had migrated to the intrathoracic cavity. The patient was operated by 

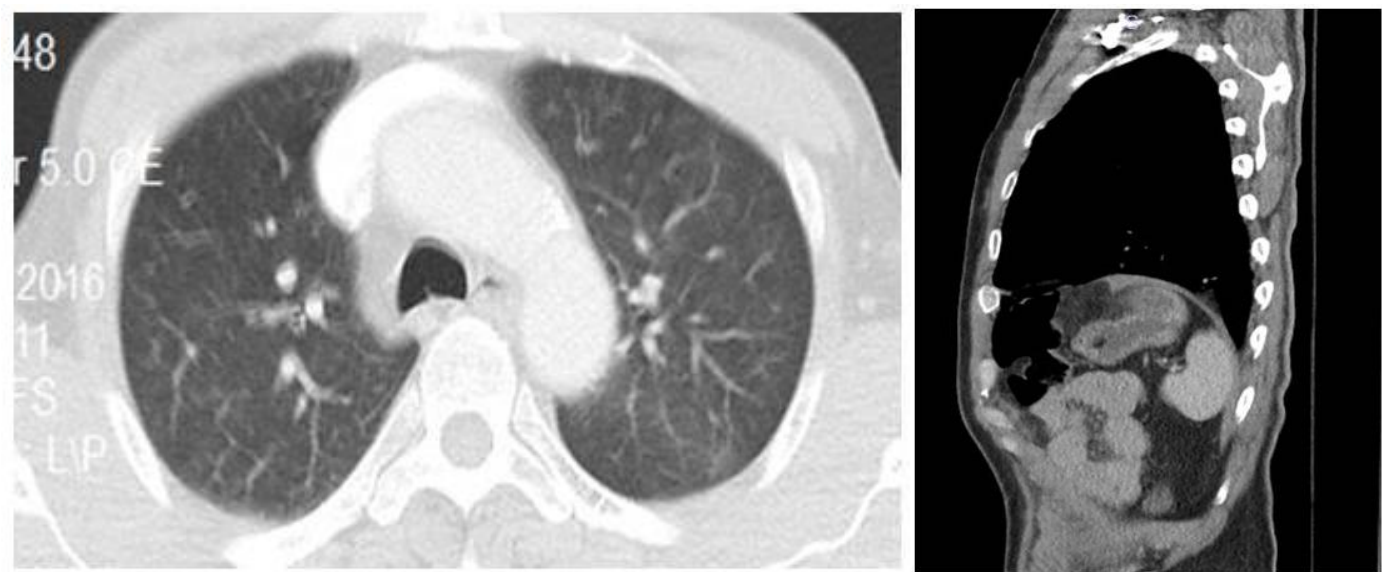

Fig. 1. a,b. Axial (a) and coronal (b) CT images show no TDR.

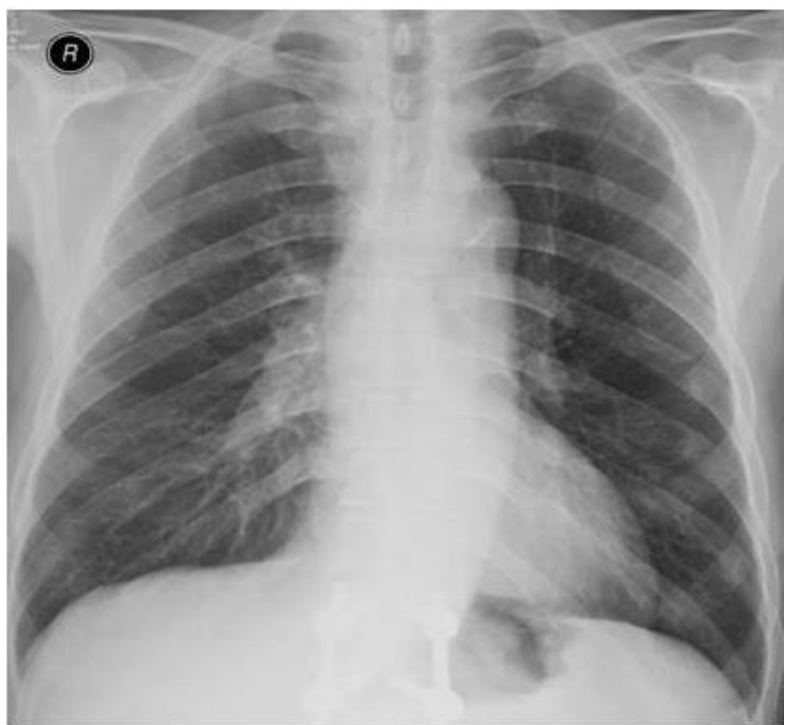

Fig. 2a. Normal postero-anterior Chest X-Ray.

the departments of general surgery and thoracic surgery and was discharged with full recovery on the 40th day of hospitalization.

\section{Discussion}

TDR occurs in $0.8-15 \%$ of cases following a significant, blunt, and penetrating thoracoabdominal trauma (5). Thiam et al. (5) found this percentage to be $1.3 \%$ in an evaluation of 1535 patients with thoracoabdominal trauma.

The main cause of TDR has been reported as a blunt trauma, and other common causes include vehicle accidents and falls from height (6). In this paper, we presented a patient who suffered from TDR due to a blunt trauma caused by tree logs falling onto him.

Lenot et al. suggested that the clinical signs and symptoms of TDR were non-specific (4). In a study conducted in Turkey, the most common
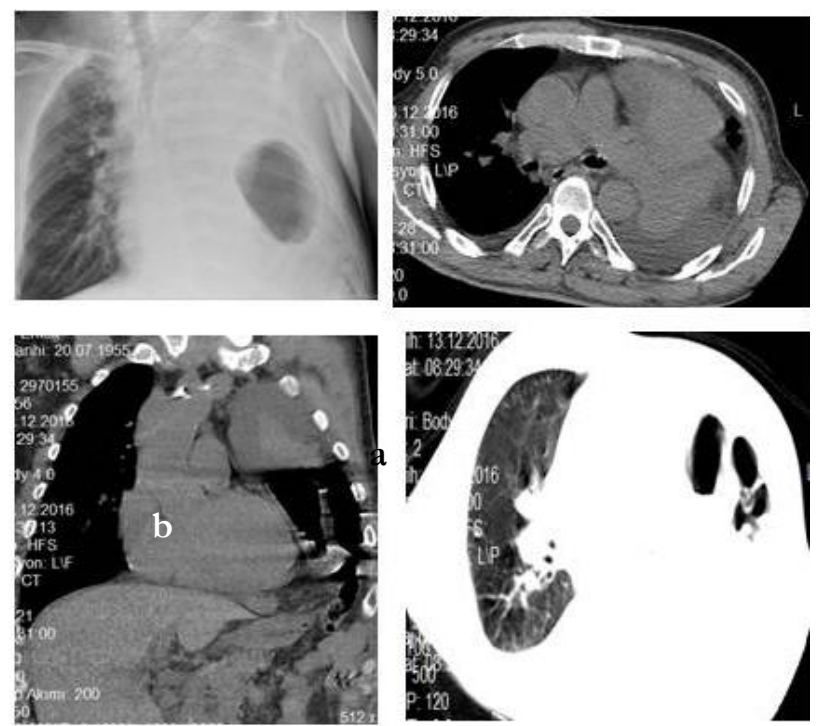

Fig. 2b. Postero-anterior Chest X-Ray, axial and coronal CT images show TDR.

signs and symptoms of TDR were reported to be chest and abdominal pain, abdominal distention, difficulty in breathing, and diminished lung sounds (7). In the current case, there had been no suggestive signs and symptoms of TDR at the moment of admission to the hospital; yet, on the following days, the patient complained about difficulty in breathing and further examination resulted in the diagnosis of TDR.

In the medical literature, it is suggested that a thoracoscopy or laparoscopy is necessary to prevent overlooking TDR in patients with a penetrating left thoracoabdominal trauma (1). Lim et al. showed that preoperative imaging had limited benefits for the diagnosis of TDR (2). Furthermore, Thiam et al. reported that diagnosis may be delayed despite the utilization of imaging methods (5). Similarly, in the presented case, the patient was diagnosed with TDR following the second thoracoabdominal CT scan undertaken on 
the second day of trauma since the initial CT taken immediately after the blunt trauma revealed no sign of a diaphragmatic rupture.

TDR does not spontaneously recover and it may cause life-threatening clinical complications (6). It has been reported that the treatment of TDR remains controversial in terms of the surgical approach and technique. Mortality is mainly related to concurrent injuries (5). Thiam et al. (5) reported the mortality rate in TDR cases as $5 \%$. Hanna et al. suggested that the Injury Severity Score (ISS) was the most widely recognized determinant of mortality in TDR cases (1). In the case presented, the ISS was 13, and the patient underwent surgery on his abdomen, after which he was discharged with full recovery.

It is a disadvantage that the priority of posttraumatic dyspnea is linked to COPD, because of the case has COPD.

In conclusion; this case report emphasizes the importance of the re-examination of patients with multiple trauma whose first tests show normal signs for the possibility that a new sign or symptom occurs later.

Conflict of interest statement: The authors declare that there are no conflicts of interest.

Financial Disclosure: The authors declared that this study has received no financial support.

\section{References}

1. Hanna WC, Ferri LE. Acute traumatic diaphragmatic injury. Thorac Surg Clin 2009; 19: 485-489.

2. Lim BL, Teo LT, Chiu MT, Asinas-Tan ML, Seow E. Traumatic diaphragmatic injuries: a retrospective review of the 12-year experience at a tertiary trauma centre. Singapore Med J 2016.

3. Vilallonga R, Pastor V, Alvarez L, Charco R, Armengol M, Navarro S. Right-sided diaphragmatic rupture after blunt trauma. An unusual entity. World J Emerg Surg 2011; 6: 3.

4. Lenot B, Bellenot F, Regnard JF, Dartevelle P, RojasMiranda A, Levasseur P. [Rupture of the diaphragm of late manifestation].[Article in French] Ann Chir 1990; 44: 157-160.

5. Thiam O, Konate I, Gueye ML, et al. Traumatic diaphragmatic injuries: epidemiological, diagnostic and therapeutic aspects.Springerplus 2016; 5: 1614 .

6. Gmachowska A, Pacho R, Anysz-Grodzicka A, et al. The Role of Computed Tomography in the Diagnostics of Diaphragmatic Injury After Blunt Thoraco-Abdominal Trauma.Pol J Radiol 2016; 81: 522-528.

7. Dübüş T, Özkarabulut C, Kaygusuz A. Gecikmiş Travmatik Diyafragma Rüptürü:Olgu Sunumu. Turkiye Klinikleri J Gastroenterohepatol 2009; 16: 36-40. 